\title{
AS CRIANÇAS E OS DIREITOS DE CIDADANIA: A CIDADE COMO COMUNIDADE EDUCADORA*
}

\author{
ANDREA FUSARI
}

\begin{abstract}
RESUMO: Em resposta às demandas detalhadas postas pelo contexto nacional italiano, nossa contribuição refere-se às políticas implementadas pela cidade de Pistóia, nesses últimos vinte anos, no sentido de construir uma rede educacional complexa de serviços para crianças; estes consistem tanto em serviços institucionais convencionais, como creches e escolas maternais, quanto em novos serviços que almejam satisfazer as necessidades que surgem numa sociedade em constante mutação. Nossa ênfase recai no trabalho desenvolvido até o momento no campo da formação profissional intercultural para promover a descoberta, troca e comparação de todas as diferenças.
\end{abstract}

Palavras-chave: Itália. Primeira infância. Serviços educacionais. Intercultura. Cidade educacional.

\section{ChILDREN AND THEIR RIGHT TO CITIZENSHIP: The Town AS THE EDUCATIONAL COMMUNITY}

ABSTRACT: In response to the detailed requests made by the national Italian context, our contribution refers to the policies carried out by the Town of Pistoia in the past twenty years of work in order to build a complex educational network of services for children; these services refer both to established institutional ones like infant toddler centers and nursery schools and also to new services that aim to satisfy the emerging needs of a rapidly changing society. Our emphasis is on the work so far carried out in the field of professional intercultural training in order to develop the meeting, exchanging and comparing of all differences.

Key words: Italy. Early childhood. Educational services. Interculture. Educational town.

\footnotetext{
* $\quad$ Este texto fez parte da Mesa Temática "Educação e políticas de Exclusão: A negação dos direitos da infância", apresentada no Fórum Mundial de Educação (outubro de 2001), Porto AlegreRS (Brasil). Traduzido por Fernanda L. Ortale e Ilse Paschoal Moreira a partir da transcrição em italiano.

** Secretário da Educação da Prefeitura de Pistóia. (Toscana, Itália). E-mail: eda.pistoia@tin.it
} 

rimeiramente, desejo, em nome da cidade de Pistóia, ${ }^{1}$ agradecer o interesse manifestado aqui pelas políticas e pelos projetos educativos realizados para as crianças e suas famílias em nossa realidade.

Nesta comunicação, vou me referir também ao quadro nacional italiano e às escolhas que o governo anterior de centro-esquerda fez no âmbito dos direitos das crianças e das políticas sociais e de formação, e que agora, diante do quadro político alterado, estamos todos empenhados em defender e ampliar. Dado o grande e significativo número de medidas legislativas durante o governo anterior, esse momento político pode ser considerado hoje, de fato, como a legislatura dos direitos das crianças. Governo e parlamento mostraram uma extraordinária sensibilidade em relação aos problemas da infância e da adolescência, aprofundando-os em um espírito unitário e assegurando vias preferenciais que permitiram a realização de importantes reformas. Foi considerada indispensável a realização de medidas específicas para apoiar o percurso de desenvolvimento da criança rumo ao amadurecimento e para garantir não somente a declaração, mas também o gozo dos direitos por parte das crianças. Da mesma forma, a qualidade da formação foi colocada como uma das mais importantes prioridades de ação e, nesse sentido, tivemos indícios bem precisos que nos permitem identificar, especificamente no investimento de esforços e recursos no sistema de formação e nas novas gerações, a garantia de uma sociedade mais segura e mais justa.

Para a atuação dos direitos das crianças e dos jovens, foi fundamental abandonar a lógica, que prevalecia no passado, caracterizada por uma abordagem assistencial e de amparo aos problemas presentes na infância e na adolescência. Nesse sentido, podemos citar algumas medidas que o governo italiano apresentou aos cidadãos e ao parlamento como fatos particularmente extraordinários.

A lei 285/97, significativamente intitulada Disposições para a promoção de direitos e de oportunidades para a infância e a adolescência, destinou fundos importantes para desenvolver medidas voltadas para apoiar o crescimento de todas as crianças, para projetos voltados para apoiar a relação pais-filhos, para enfrentar a pobreza e a violência, para desenvolver medidas alternativas à internação de crianças em instituições (promovendo a prática da responsabilidade familiar), para inovar os serviços sócio-educativos, para realizar ações positivas para a reivindicação de direitos, para desenvolver ações de apoio às famílias com crianças deficientes. 
Após alguns anos de aplicação, podemos afirmar, seguramente, que a lei influiu positivamente na situação da infância e da adolescência. Influiu positivamente não apenas por ter trazido recursos e desenvolvido novos serviços, mas também por ter estimulado um novo modo de organizar o trabalho e as ações sociais e educativas voltadas para as crianças, para os jovens e para suas famílias.

Se pretendermos obter elementos novos no futuro, é necessário destacar o esforço para intervir de modo orgânico e coordenado, reconstruindo uma política da criança não fragmentada, mas reconduzida à unidade "pela compreensão da vida como um conjunto único, marcado pelas várias fases evolutivas do crescimento e da formação pessoal". A premissa é que o bem-estar das crianças e dos jovens não pode surgir repentinamente de forma espontânea em determinado ponto das suas vidas, mas nasce somente como conseqüência de um trabalho paciente e tenaz de socialização da cultura e de enriquecimento progressivo.

O projeto propõe-se a objetivos ambiciosos como:

A realização de programas sócio-educativos para a primeira infância e para os pais; programas que não são substitutos das creches tradicionais, mas que se apresentam como projetos mais limitados nos objetivos e mais flexíveis em relação às exigências das famílias.

A organização de centros educativos e recreativos destinados ao lazer dos jovens, a fim de oferecer oportunidades de formação mesmo durante o período de férias.

$\mathrm{O}$ apoio à multiplicidade de ações orientadas para a qualificação dos espaços urbanos e para a melhoria da qualidade de vida das crianças e dos jovens dentro da cidade.

Uma outra medida legislativa importante no setor escolar foi a aprovação definitiva da reforma dos ciclos de instrução, que redefiniu a escola de base, a integração da pré-escola e a requalificação do ensino secundário. ${ }^{2}$ É uma reforma que se propõe a equiparar a Itália a todos os outros países europeus, elevando o ciclo obrigatório de oito para dez anos e tornando obrigatório o último ano de freqüência da pré-escola. Podemos presumir que, não obstante a hostilidade do atual governo, esses fundamentos não serão recolocados em discussão.

As observações que fiz em relação ao quadro nacional exprimem a vitalidade e a riqueza de um debate muito acirrado que não se mostra absolutamente resolvido, mas que é, certamente, estimulante para uma reflexão mais profunda sobre os direitos da infância. Políticos e especialistas 
estão discutindo sobre as estratégias e as modalidades que asseguram bem-estar e formação não apenas durante o período escolar, mas também durante todo o tempo de vida do jovem.

Podemos dizer que Pistóia está em dia em relação às exigências tão complexas e articuladas que provêm do contexto nacional. $\mathrm{Na}$ nossa cidade, trabalhamos, de fato, para construir uma rede de serviços que se estenderam gradualmente das crianças menores para as maiores, mas, paralelamente, trabalhamos muito para unir os diversos serviços e as diversas propostas, que se referem tanto a modelos institucionais consolidados como também a novas tipologias de ações que visam responder às necessidades emergentes de uma sociedade em rápida transformação.

A Prefeitura de Pistóia trabalhou, nos últimos anos, com um investimento particularmente significativo quanto às escolhas orçamentárias, as quais estamos empenhados em garantir também para o futuro, e que permitiu integrar a proposta educativa pública nos diversos tipos de escola com realizações de significado particular:

As creches e as pré-escolas municipais para a faixa de 0-6 anos;

As oficinas de jovens de Pistóia que, com seus roteiros didáticos, integram a experiência escolar dos jovens e enriquecem o seu tempo livre;

As "Areebambini”3 e o CIAF (Centro de Infância, Adolescência e Família) que se caracterizam como locais educativos diferentes da instituição escolar, com projetos mais limitados, voltados para diferentes faixas etárias e diferentes momentos do dia.

Devo dizer que o nosso percurso de trabalho implica um esforço coletivo feito de acordos, de sensibilidade, de motivações, que assumiu um grande valor para toda nossa cidade. Creches, pré-escolas, areebambini, oficinas, bibliotecas juvenis, CIAF formaram, no decorrer dos últimos anos, uma rede articulada e flexível de espaços educativos para as crianças e suas famílias.

Contudo, teria sido um erro fatal delegar a função educadora em sentido global unicamente aos serviços educativos, a qual deve necessariamente pertencer a toda a sociedade nas suas diversas articulações: a família, a comunidade, o próprio tecido urbano. O esforço e o objetivo da administração foi, conseqüentemente, o de estender as próprias ações além dos serviços para a infância e além do tempo na escola, a fim de recompor, mesmo dentro da malha da cidade, espaços receptivos e familiares, oportunidades de jogo e de crescimento durante o tempo 
livre, oportunidades - mesmo para as crianças menores -, de microexperiências para serem vividas de modo autônomo e, de modo mais geral, produzir situações e contextos educativos em que toda a comunidade possa se encontrar em uma dimensão mais humana e gratificante do viver.

O projeto $A$ cidade educadora - Pistóia amiga das crianças e dos jovens é o ponto de chegada de uma base política na qual o administrador municipal investiu e quer investir para garantir qualidade e acessibilidade aos serviços educativos para a infância, para construir uma cidade mais acolhedora, mais segura, realmente amiga das crianças e dos jovens, tendo certeza de que uma cidade que dá margens crescentes de autonomia e liberdade às crianças é uma cidade na qual haverá mais motivos para que os adultos também vivam bem.

A partir dessa perspectiva, surgiu a necessidade de recuperação do papel central do espaço urbano na vida da coletividade e, em particular, das crianças, as quais freqüentemente são obrigadas a passar o tempo livre nos ambientes domésticos. Enquanto digo tudo isso, sinto necessidade de falar sobre a idéia de pluralidade da infância, porque sabemos que, no mundo, há muitos modos diferentes ser criança e existem modos muito diferentes de atravessar essa fase da vida. Vemos crianças que vivem trancadas entre quatro paredes, para as quais é necessário promover ações que lhes devolvam a rua como lugar de experiência e de encontro e, ao mesmo tempo, sabemos que há realidades em que as crianças têm apenas a rua e, portanto, é necessário promover uma rede de percursos e de suportes formadores.

As nossas crianças talvez tenham muita escola, certamente muita televisão e computador, em contextos sociais e familiares cujas relações afetivas estão cada vez mais (e infelizmente) mediadas e substituídas por mercadorias e bens de consumo da nossa distorcida opulência. Têm, ao contrário, pouco ou nada no que diz respeito a brincadeiras e à convivência, em um mundo reduzido à casa, ou pior, à sala de TV, na qual raramente há um animal; um mundo homologado em que se vive apenas entre os coetâneos. A cidade e os espaços abertos representam, para elas, um horizonte a ser conquistado.

Com essa prerrogativa, nos últimos anos, um cartaz permanente de atividades, $A$ cidade em jogos, apresenta programações nos fins de semana para crianças e jovens em jardins, edifícios históricos, museus locais, ruas e praças oportunamente livres de automóveis e motos, com muitas e variadas propostas de encontros: espetáculos de 
marionetes e artistas de rua, caça ao tesouro, programas de jogos e de visita a museus, oficinas de atividades criativas, competições de bicicleta, concertos de jovens, apresentações com personagens e músicas de historinhas escritas pelas crianças, redescoberta de velhos jogos de rua; freqüentemente auxiliadas pela colaboração de associações ambientalistas, culturais, de voluntários e também de pequenos grupos espontâneos de pais.

A idéia de garantir às crianças o pleno direito de cidadania encontra-se na base de iniciativas realizadas nestes últimos anos, como, por exemplo, os caminhos seguros perto da escola, para encorajar as crianças a enfrentar a pé o trânsito urbano; as lojas amigas das crianças, em que na vitrine está escrito que crianças e adultos podem entrar quando precisarem - um tipo de sinalização elaborada na cidade para ajudar as crianças menores a reconhecer os lugares dedicados às suas atividades de movimento, de jogo e de aprendizagem: jardins, escolas, ginásios de esporte, bibliotecas e piscinas.

Foi realizado o Ludobus: um velho ônibus escolar da garagem da Prefeitura foi transformado, tanto por fora quanto por dentro, em um meio para veicular propostas de jogos e de aprendizagem mesmo nos locais mais distantes da cidade.

Entretanto, a promoção dos direitos não se destina exclusivamente à infância e à adolescência do nosso país; ela está voltada também para todos os menores presentes na nossa realidade e que provêm de lugares pouco ou muito distantes.

Está aumentando, na Itália e na nossa cidade, a sensibilidade em relação às crianças, aos jovens estrangeiros e às suas famílias; há uma maior atenção às suas exigências, um sentimento de solidariedade mais forte para diminuir suas dificuldades, tanto no país de origem quanto na chegada e no apoio à integração da sua cultura.

Nossas cidades assistem à presença, cada vez mais freqüente e tangível, de mães e crianças pequenas, provenientes de outras culturas, que timidamente nos circundam e que suscitam, ao mesmo tempo, perguntas e curiosidades. Da tipologia migratória inicial, caracterizada por uma maciça presença de homens e jovens, passamos a assistir a um momento em que se encontra fortemente o fenômeno de união das famílias, a reconstrução do núcleo familiar; fenômeno que desloca necessariamente a atenção em direção às mulheres e às crianças - pessoas cuja imagem deixa transparecer uma condição de solidão, isolamento, desambientação e fragilidade. A criança que encontramos traz consigo 
uma bagagem de emoções e de sentimentos que estão estritamente ligados à sua idade, às condições econômicas familiares, à sua situação de moradia, à sua história pessoal migratória.

A idéia de que as crianças estrangeiras representem um tipo de "futuro que se aproxima" e que, como futuros cidadãos, sejam portadoras de uma sociedade de fato multiétnica e multicultural, nos faz refletir e oferecer serviços e meios que as ajudem a se familiarizar com as novas situações nas quais se encontram. Daí a idéia cada vez mais forte e atenta para a elaboração de modalidades adequadas para acolhê-las, de estratégias pensadas a fim de que seu percurso escolar seja bem sucedido. Por isso, nos últimos anos, a administração municipal promoveu iniciativas voltadas para criar incentivo e sensibilidade em relação a essas mudanças que atingem o nosso tecido social.

O congresso Infância e Infâncias, realizado em novembro de 2000, foi um evento nacional, ponto de chegada de um percurso em prática por tantos anos, que muitas escolas italianas e, em particular, uma escola de Pistóia realizaram, desenvolvendo uma colaboração e uma troca com as Oficinas do Saber de Florianópolis, aqui no Brasil. Um projeto muito profícuo, que produziu resultados significativos no que se refere à formação intercultural e soube realizar, nos últimos anos, uma experiência particularmente intensa, um laço particularmente profundo entre essas duas realidades. A certeza que extraímos do projeto é que, hoje, é estratégico desenvolver dinâmicas de encontro, conhecimento e comparação entre todas as diversidades, favorecer a coexistência de culturas diferentes. Com essa finalidade, abrimos neste ano uma nova oficina especificamente voltada para a formação intercultural, dirigida tanto para crianças estrangeiras e suas famílias quanto para crianças de Pistóia e seus pais; para deixar claro que, na base desses trabalhos, não há uma intenção exclusivamente solidarista, mas a consciência da necessidade de uma troca, de uma contaminação, em que ambas as partes possam crescer juntas.

A Europa descobriu 'o outro' no âmbito da contraposição e do domínio. Costumava-se usar o seguinte ditado: "o homem que pertence a duas culturas perde sua alma”. Nós podemos, ainda hoje, aceitar o fascínio, ou melhor, o encanto dessa expressão poética. Porém, não acreditamos mais nela. Sabemos, ao contrário, que hoje é o momento de tecer o elogio da pluralidade das culturas, de reforçar a mistura de vozes, de onde somente pode vir um futuro para as nossas comunidades.

O desafio dos nossos tempos consiste, exatamente, neste colocar em jogo a identidade. Confiantes de que se abrir a tradições e culturas 
diferentes não quer dizer perder a própria alma, mas que, ao contrário, é o único modo de dar forma a um futuro mais sereno e solidário para os nossos filhos e para as gerações futuras.

Recebido em novembro de 2001.

Aprovado em fevereiro de 2002.

\section{Notas}

1. N. do T.: Pistóia é uma cidade localizada na região da Toscana, norte da Itália.

2. N. do T.: Em italiano "ensino secondario". Na Itália, o ensino secondário refere-se tanto ao "ensino secondario inferiore", que corresponde aos quatro últimos anos no Ensino Fundamental, quanto ao "ensino secondario superiore", que corresponde ao Ensino Médio no Brasil.

3. N. do T.: "Áreascrianças" em tradução livre. 